\title{
Directivity Enhancement of a Broadband Printed Antenna by Using Two Closely Spaced Strips
}

\author{
Jiangniu $W u(\mathbb{D}$, Jing Sun, and Jinyong Fang \\ Xi'an Branch, China Academy of Space Technology, Xi'an 710100, China \\ Correspondence should be addressed to Jiangniu Wu; wujiangniu515@163.com
}

Received 29 May 2021; Accepted 13 September 2021; Published 7 October 2021

Academic Editor: Muhammad Ramlee Kamarudin

Copyright (C) 2021 Jiangniu Wu et al. This is an open access article distributed under the Creative Commons Attribution License, which permits unrestricted use, distribution, and reproduction in any medium, provided the original work is properly cited.

\begin{abstract}
The bandwidth of a printed rectangular loop antenna with two gaps can be enlarged by using the metallic strips as directors. However, the directivity is not good. Because the two closely spaced metallic strips act as a building block, they can be used to block the propagation of electromagnetic waves. Therefore, two closely spaced metallic strips as a new reflector are adopted and investigated in this paper for improving the directivity of antenna. Two arrangement modes of the printed antennas with two closely spaced strips are designed, fabricated, and measured. Experimental results show that the impedance bandwidth of type A antenna (with inner strip) is about $62.5 \%$ ranging from 2.3 to $4.39 \mathrm{GHz}$. In addition, the gain of $3.8-5.2 \mathrm{dBi}$ and $2 \mathrm{~dB}$ improvement of F/B ratio are achieved. Type B antenna (with outer strip) can realize a $62 \%$ measured bandwidth ranging from 2.29 to $4.35 \mathrm{GHz}$. Also, about 3.4 to $4.9 \mathrm{dBi}$ of gain with $2.5 \mathrm{~dB}$ improvement of $\mathrm{F} / \mathrm{B}$ ratio is obtained. The measured $\mathrm{F} / \mathrm{B}$ ratios of the two modified antennas are both better than $10 \mathrm{~dB}$ within the operating frequency band. Measured results verified that adopting the two closely spaced metallic strips as a new reflector can both enhance the F/B ratio and gain without changing the overall dimensions and operating frequency.
\end{abstract}

\section{Introduction}

With the rapid development of wireless communication systems, the need for wide impedance bandwidth and lowprofile antennas with good electrical characteristics is ever demanding $[1,2]$. In some cases, for example, for point-topoint high-speed data communications and short-range wireless local networks, the antennas with unidirectional radiation patterns are required to suppress the unwanted interference signals and optimize the power efficiency or coverage range $[3,4]$.

The printed Yagi antenna is a prevalent option in many applications due to its simple structure and unidirectional radiation characteristics [5]. The typical configuration of this antenna consists of a driven element (driver) and some parasitic elements, including a reflector and one or more directors. The radiation resistance of this antenna drops quickly along with the decrease of spacing between the elements, which will lead to low radiation efficiency [6-8]. For some cases, the radiation resistance drops to $50 \Omega$ in the special frequency point. Good impedance matching can be achieved, and a new resonant frequency point can be induced [9]. This type antenna has a good directivity but has the drawback of narrow band characteristics.

By introducing two gaps in the printed rectangular loop, the bent strip at the bottom acts as a reflector. Then, the printed rectangular loop antenna can be regarded as a printed bent Yagi antenna [10]. A good cardioid unidirectional radiation characteristic is achieved. However, this printed antenna has a relatively narrow bandwidth. In order to extend the impedance bandwidth, a strip was adopted in [11]. The bandwidth was greatly expanded, and a $40.7 \%$ measured bandwidth was obtained. Another metal strip was also added at the maximum radiation direction of the loop in [12] for further increasing the directivity. However, owing to the drawback of narrow characteristics of single strip, the antenna directivity will be decreased when the new resonant frequency points are designed far away from the original one decided by the loop. 
In this paper, the aim is to improve the antenna directivity. Because the two closely spaced metallic strips act as a building block, they can be used to block the propagation of electromagnetic waves [13]. Then, the two closely spaced metallic strips can block the propagation of electromagnetic waves. Therefore, the two closely spaced metallic strips are adopted as a new reflector to improve the F/B ratio in this paper. Two arrangement modes of the printed antennas with closely spaced metal strips are designed, fabricated, and measured. Both simulation and measured results demonstrate the effectiveness of the proposed designed arrangement modes.

\section{Performance of the Reference Antenna}

Due to the introduced two gaps, the rectangular loop antenna presented in [10] can be regarded as a two-element printed Yagi antenna. Thus, a unidirectional radiation characteristic is achieved. The input impedance decreases at the high-frequency resonant point and the impedance matching is improved when a metallic strip is added. A wide impedance bandwidth was obtained in [11]. However, the impendence matching and directivity are limited by the metallic strip. In order to further increase the impendence bandwidth and improve the directivity, another metallic strip as a new director is added at the maximum radiation direction [12].

The structure and parameters of the reference antenna in [12] are depicted in Figure 1(a). This antenna is printed on a FR4 substrate with dielectric constant of 4.4 and thickness of $0.4 \mathrm{~mm}$. This antenna utilizes two metallic strips for further improving the impedance matching and antenna directivity. As shown in Figure 1(a), the two strips (strip 1 and strip 2) are placed in the maximum radiation direction of the rectangular loop antenna. A port with $50 \Omega$ characteristic impedance is used to feed the antenna for simulations.

Here, the effects of the strip 1 and strip 2 are firstly discussed. Figure 2 shows the comparison of the rectangular loop with only strip 1 and with two strips (strip 1 and strip 2 ). As shown in Figure 2, the impedance matching is further improved when strip 2 is added to the maximum radiation direction. Another new resonant frequency point appears at the higher frequency band. In addition, the impedance matching between the first resonant frequency point and the second resonant frequency point is also improved due to the introduced strip 2. Thus, the bandwidth is further enlarged and a wider bandwidth is obtained. The simulated $\mathrm{F} / \mathrm{B}$ ratio is also plotted in Figure 2. It is observed that about $9 \mathrm{~dB}$ of F/ $\mathrm{B}$ ratio at $3.1 \mathrm{GHz}$ is achieved when strip 2 is introduced. Compared with the result of rectangular loop antenna with only strip 1 , the $\mathrm{F} / \mathrm{B}$ ratio has been increased about $1.5 \mathrm{~dB}$. However, the antenna directivity is still not good.

The optimized parameters of the reference antenna in [12] are as follows: $d_{1}=10.2 \mathrm{~mm}, d_{2}=4 \mathrm{~mm}, d_{3}=6 \mathrm{~mm}$, $w_{0}=2.2 \mathrm{~mm}, w_{1}=2.2 \mathrm{~mm}, w_{2}=2.2 \mathrm{~mm}, \quad g=1.4 \mathrm{~mm}$, $g_{1}=0.8 \mathrm{~mm}, g_{2}=2.8 \mathrm{~mm}, l_{1}=38.4 \mathrm{~mm}, l_{2}=25 \mathrm{~mm}$, and $l_{3}=24.6 \mathrm{~mm}$. The photographs of the fabricated reference antenna are shown in Figure 3. A flexible $50 \Omega$ coaxial cable is used to feed the fabricated antenna for the measurement. The fabricated antenna is measured by using an Agilent
E8363B programmable network analyzer (PNA) and SATIMO measurement system.

The simulated and measured reflection coefficients of the loop antenna with two strips (strip 1 and strip 2) are shown in Figure 4. Good agreement between the simulations and measurements can be observed. The measured bandwidth is approximately $63.1 \%$ ranging from 2.29 to $4.4 \mathrm{GHz}$, which is larger than that of the loop antenna without or only with strip 1 (the bandwidths of the antenna without and with strip 1 are about $12.7 \%$ and $40.6 \%$ according to the measured results in [11]). This proves that the impedance bandwidth has been greatly enlarged by adding the new strip 2 .

The gain of the reference antenna is also shown in this figure. In the operating band, the minimum gain is at $3.1 \mathrm{GHz}$ with a value of $3.5 \mathrm{dBi}$ and the maximum gain is at $2.3 \mathrm{GHz}$ with a value of $4.9 \mathrm{dBi}$. The measured gain is higher than $3.5 \mathrm{dBi}$ with a variation of $1.5 \mathrm{~dB}$ in the band from 2.29-4.4 GHz. The gain drops down quickly when the frequency is higher than $4.4 \mathrm{GHz}$. This is mainly caused by the impedance mismatching at the high-frequency band.

Figure 5 plots the measured and simulated radiation patterns of the reference antenna in the E-plane (xoy-plane) and H-plane (yoz-plane) at 2.5, 3.0, 3.5, and $4 \mathrm{GHz}$, respectively. It is observed that the simulated results and measurement results match well. As shown in the figure, the reference antenna has unidirectional radiation characteristics. More importantly, the main lobes of the radiation patterns are fixed to the endfire direction ( $y$-axis direction) within the effective working frequency band. Stable radiation directivity can be observed.

The measured $\mathrm{F} / \mathrm{B}$ ratio of the reference antenna is depicted in Figure 6. According to the measured results, the $\mathrm{F} / \mathrm{B}$ ratio is more than $8.1 \mathrm{~dB}$ of the operation frequency band $(2.29-4.4 \mathrm{GHz})$. The radiation efficiency of the fabricated antenna is also shown in this figure. For most of the operation frequency band, this antenna has high radiation efficiency around $80 \%$. However, the $\mathrm{F} / \mathrm{B}$ ratio of this antenna is not enough for the unidirectional radiation application. If this antenna is to be used in point-to-point communication systems, the directivity of the reference antenna needs to be further improved. In the next section, two closely spaced metallic strips are adopted to improve the antenna directivity without changing the overall antenna dimensions and the operating frequency band.

\section{Antenna Designs with Improved Directivity by Using Two Closely Spaced Strips}

As mentioned in the Section 2, the F/B ratio of the reference antenna in [12] at the center frequency is about $8.1 \mathrm{~dB}$, which is not enough for a unidirectional radiation antenna. In this section, the F/B ratio of the reference antenna is improved. Because the two closely spaced metallic strips act as a building block [13], the two closely spaced metallic strips can block the propagation of electromagnetic waves. For the printed rectangular loop antenna with two gaps, two closely spaced metal strips at the bottom of antenna are adopted as a 


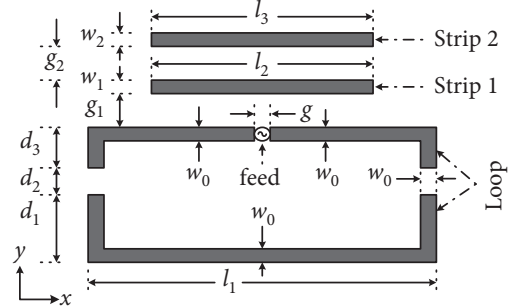

(a)

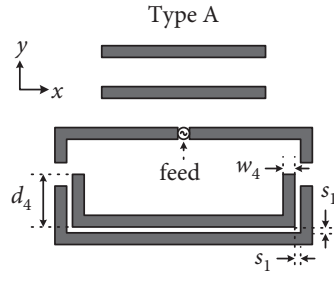

(b)

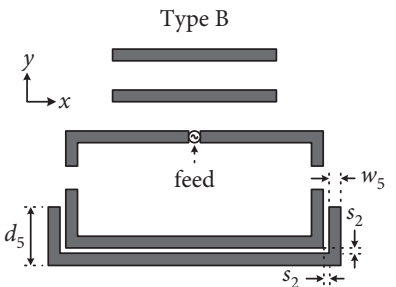

(c)

Figure 1: Geometries and parameters of the broadband printed antennas. (a) The reference antenna in [12] and two arrangement modes of the proposed printed antennas by adopting two closely spaced strips for directivity enhancement. (b) Type A antenna with inner strip. (c) Type B antenna with outer strip.

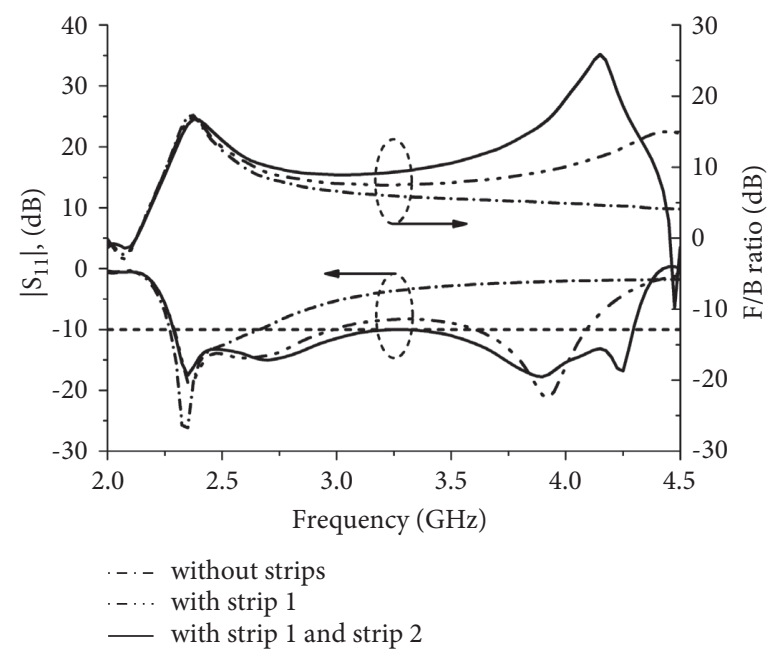

FIgURE 2: Comparison of the printed rectangular loop antenna with only strip 1 and with two strips (strip 1 and strip 2) on reflection coefficient and F/B ratio for the reference antenna.
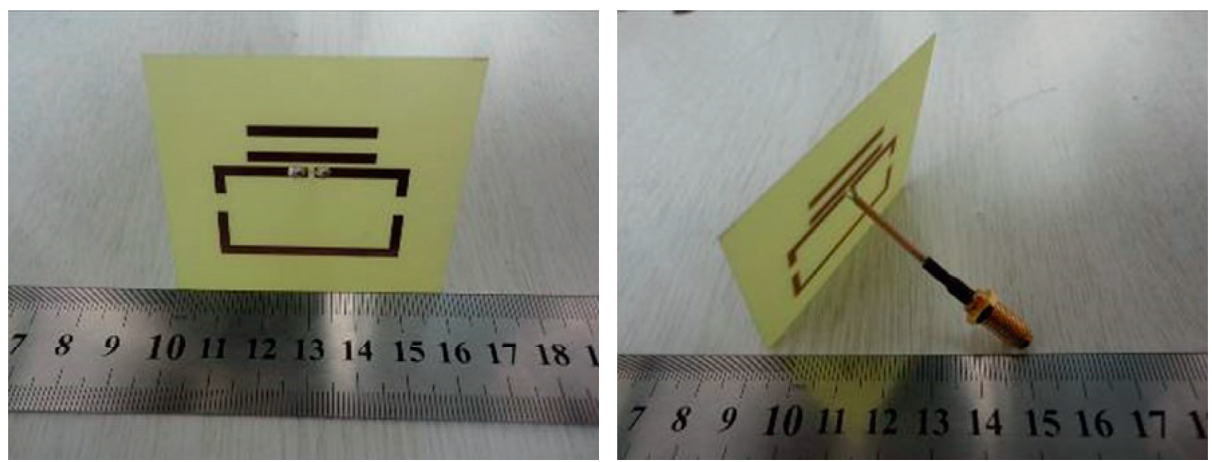

FIgURE 3: Photographs of the fabricated reference antenna.

new reflector to improve the $\mathrm{F} / \mathrm{B}$ ratio of reference antenna. When the lengths of the two closely spaced metallic strips are set to different values, the two closely spaced metallic strips can provide a wideband reflection capability. Then, a higher directivity with wide impedance bandwidth can be achieved.

In order to demonstrate the effectiveness of the above method, two arrangement modes of the antenna with two closely spaced strips are designed. The structures of the improved antennas by using two closely spaced metallic strips at antenna bottom are also depicted in Figures 1(b) and 1(c). The antenna shown in Figure 1(b) is named as type A antenna and the one shown in Figure 1(c) is named as type B antenna. All the antennas are printed on a piece of FR4 substrate with a dielectric constant of 4.4 and a thickness of $0.4 \mathrm{~mm}$. A port with $50 \Omega$ characteristic impedance is used to feed the two antennas for studying their radiation characteristics. 


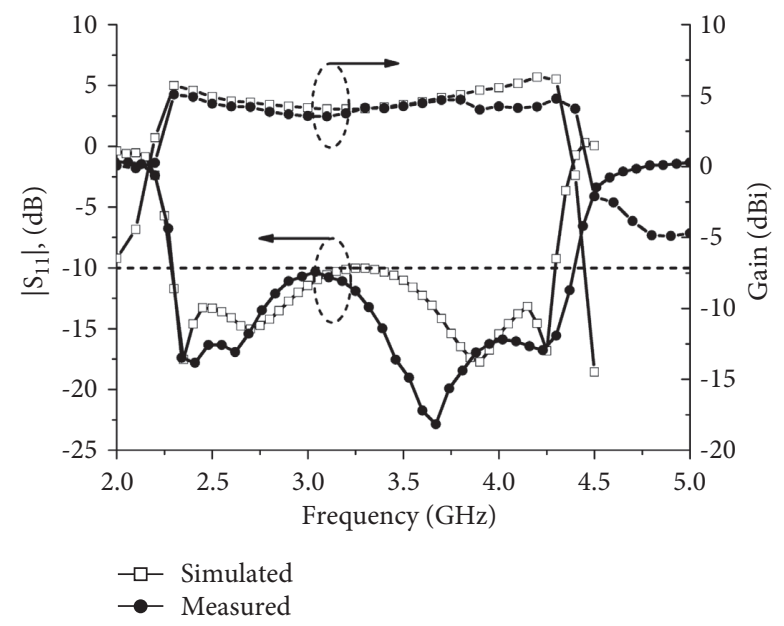

FIgURE 4: Simulated and measured reflection coefficients of the reference antenna.

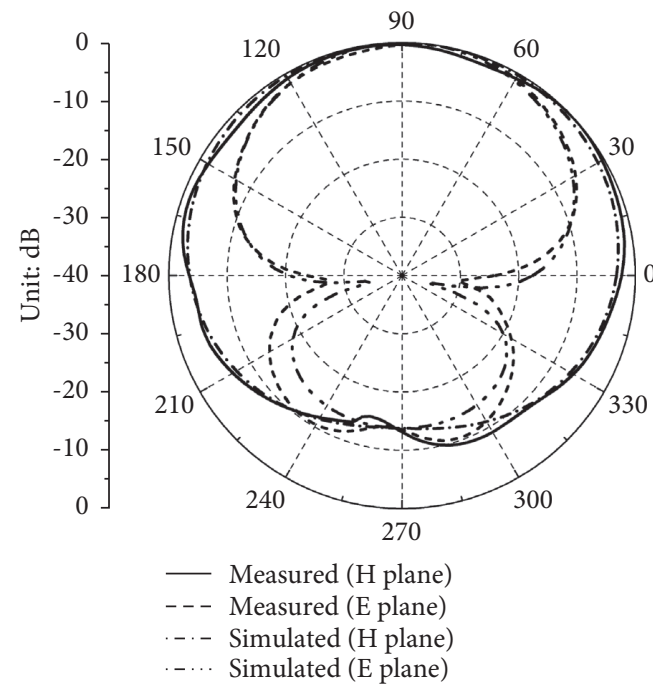

(a)

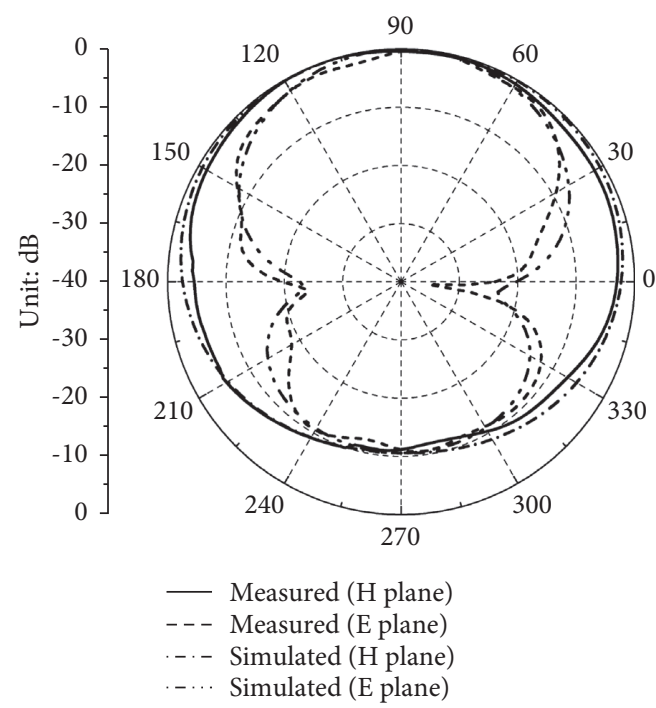

(c)

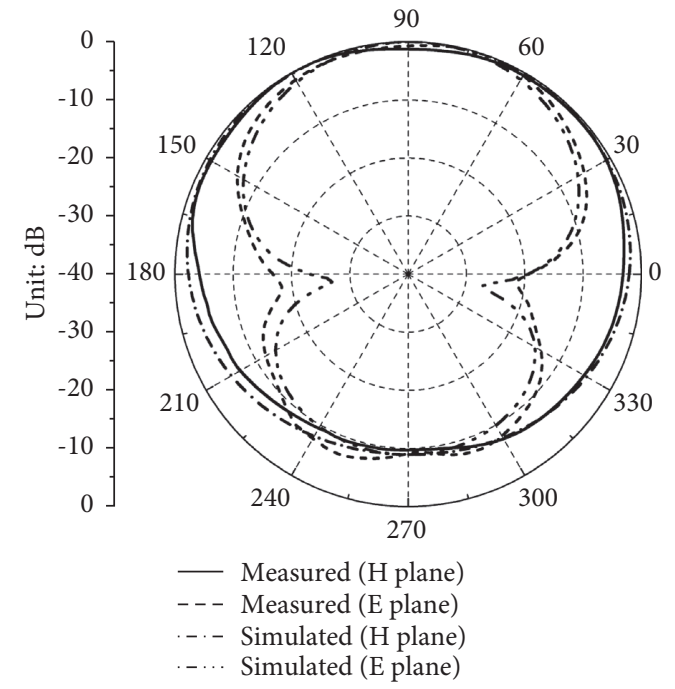

(b)

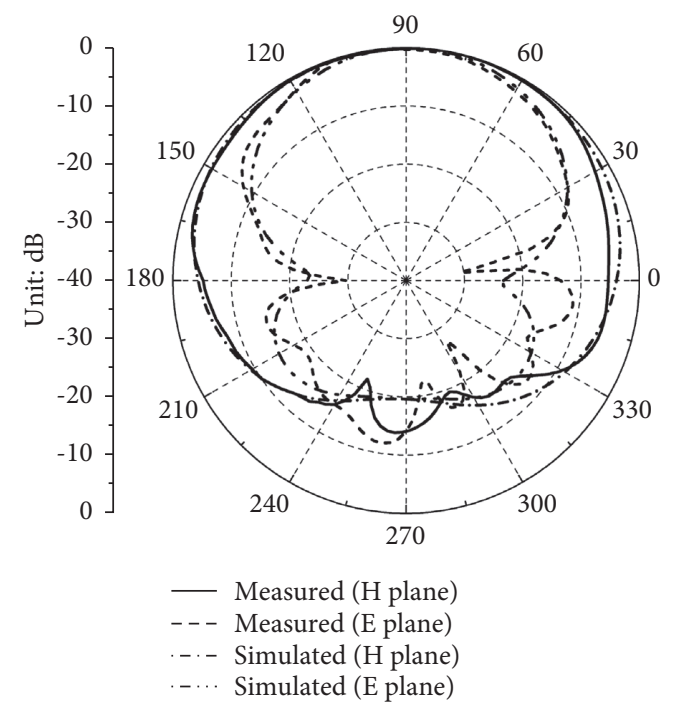

(d)

FIGURE 5: Simulated and measured radiation patterns of the reference antenna in both E-plane (xoy-plane) and H-plane (yoz-plane) at different frequencies: (a) $2.5 \mathrm{GHz}$, (b) $3.0 \mathrm{GHz}$, (c) $3.5 \mathrm{GHz}$, and (d) $4 \mathrm{GHz}$. 


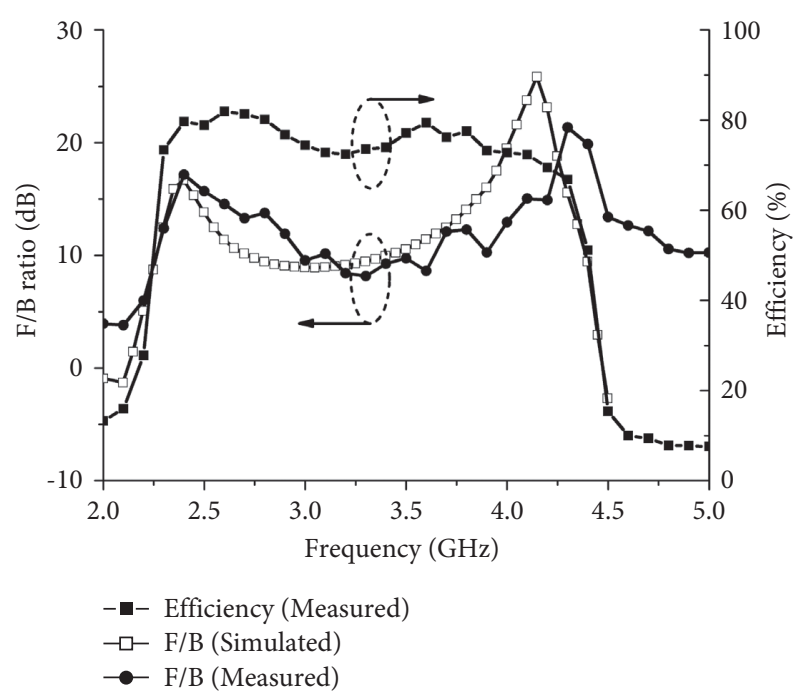

Figure 6: Measured $\mathrm{F} / \mathrm{B}$ ratio and radiation efficiency of the reference antenna in [12].

Figure 7 shows the simulated reflection coefficients and the $\mathrm{F} / \mathrm{B}$ ratios of three types of antennas, which are the reference antenna in [12], type A antenna, and type B antenna, respectively. As shown in Figure 7, the impedance matching of antenna is slightly changed when a new strip is closely added to the bottom strip. However, the antenna with new strip arranged as type $\mathrm{A}$ or type $\mathrm{B}$ has a higher $\mathrm{F} / \mathrm{B}$ ratio compared with that of the reference antenna in the whole operating frequency band. This means that adopting the two closely spaced strips as a new reflector is very effective to improve the antenna directivity. A wideband reflection capability can be provided by using the two bent closely spaced metallic strips to replace the bottom single bent strip.

During the optimization, the parameters of the two bent closely spaced strips are mainly optimized. By optimization, the final optimized parameters of the antenna are as follows: $d_{1}=10.2 \mathrm{~mm}, \quad d_{2}=4 \mathrm{~mm}, \quad d_{3}=6 \mathrm{~mm}, \quad w_{0}=2.2 \mathrm{~mm}$, $w_{1}=2.2 \mathrm{~mm}, \quad w_{2}=2.2 \mathrm{~mm}, \quad g=1.4 \mathrm{~mm}, \quad g_{1}=0.8 \mathrm{~mm}$, $g_{2}=2.8 \mathrm{~mm}, l_{1}=38.4 \mathrm{~mm}, l_{2}=25 \mathrm{~mm}$, and $l_{3}=24.6 \mathrm{~mm}$. The additional parameters for type A antenna are $w_{4}=1.9 \mathrm{~mm}$, $s_{1}=0.15 \mathrm{~mm}$, and $d_{4}=10.6 \mathrm{~mm}$, and the parameters for type B antenna are $w_{5}=2.1 \mathrm{~mm}, s_{2}=0.3 \mathrm{~mm}$, and $d_{5}=8 \mathrm{~mm}$.

In order to demonstrate the effectiveness of the improved designs, the prototypes of the proposed two arrangement modes are fabricated and measured. The photographs of the fabricated antennas are shown in Figure 8. The left one is type A antenna with inner strip and the right one is type B antenna with outer strip. Two flexible $50 \Omega$ coaxial cables similar to those in $[7,11,12]$ are used to feed the fabricated antennas for the measurement. For each antenna, the inner conductor of coaxial cable is connected to one arm of the bent dipole of rectangular loop antenna while the outer conductor of the coaxial cable is soldered to another arm. The impedance bandwidths of the fabricated antennas are obtained by using an Agilent E8363B programmable network analyzer (PNA). Also, the realized gain and radiation patterns of the fabricated antenna are obtained by using the SATIMO antenna measurement system.

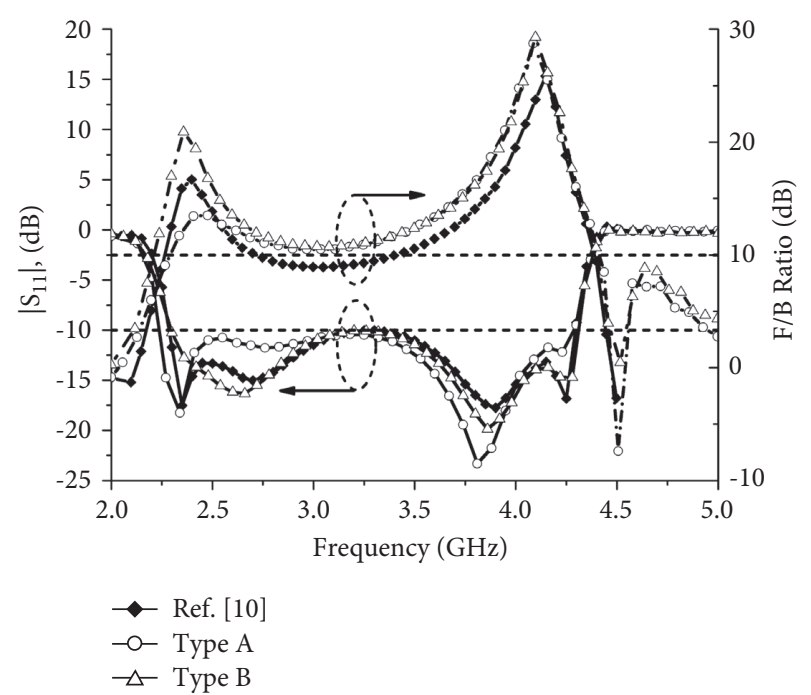

Figure 7: Comparison of simulated reflection coefficients and F/B ratios of the reference antenna and proposed improved antennas of type A and type B.

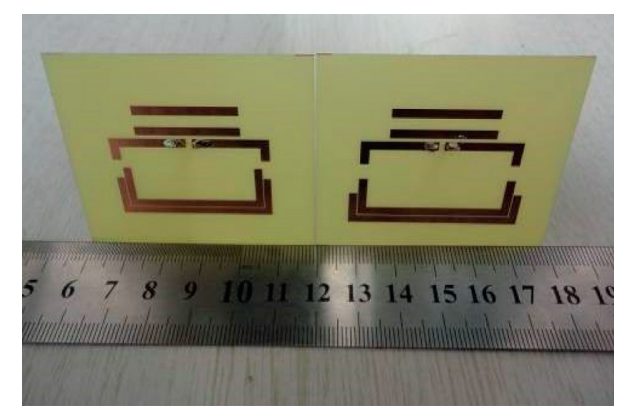

FIgURE 8: Photographs of the fabricated improved antennas (the left one is type A antenna and the right one is type B antenna).

3.1. Type A Antenna. The photograph of type A antenna is shown on the left-hand side of Figure 8. The simulated and measured reflection coefficients of type A antenna are shown in Figure 9. According to the measured results, the bandwidth of type A antenna is about $62.5 \%$ ranging from 2.3 to $4.39 \mathrm{GHz}$. The impedance bandwidth shrinks little compared with the result in Figure 4 due to the added inner strip. The measured gain of type A antenna is also shown in Figure 8. In the band between 2.3 and $4.39 \mathrm{GHz}$, the minimum gain is at the frequency of $4.3 \mathrm{GHz}$ with a value of $3.8 \mathrm{dBi}$ and the maximum gain is at the frequency of $2.3 \mathrm{GHz}$ with a value of $5.2 \mathrm{dBi}$. In other words, the measured gain is better than $3.8 \mathrm{dBi}$ in the whole operating frequency band. The realized gain is improved by adding the inner strip closely to the bottom strip compared with the reference antenna in [12]. As the frequency goes up, the gain decreases a little.

The simulated and measured radiation patterns of type $\mathrm{A}$ antenna in E-plane (xoy-plane) and H-plane (yoz-plane) at $2.5,3.0,3.5$, and $4 \mathrm{GHz}$ are depicted in Figure 10. It is observed that the experiment measurements are in agreement with the simulated results. In the operating frequency band, the main lobes of the radiation patterns are fixed to the 


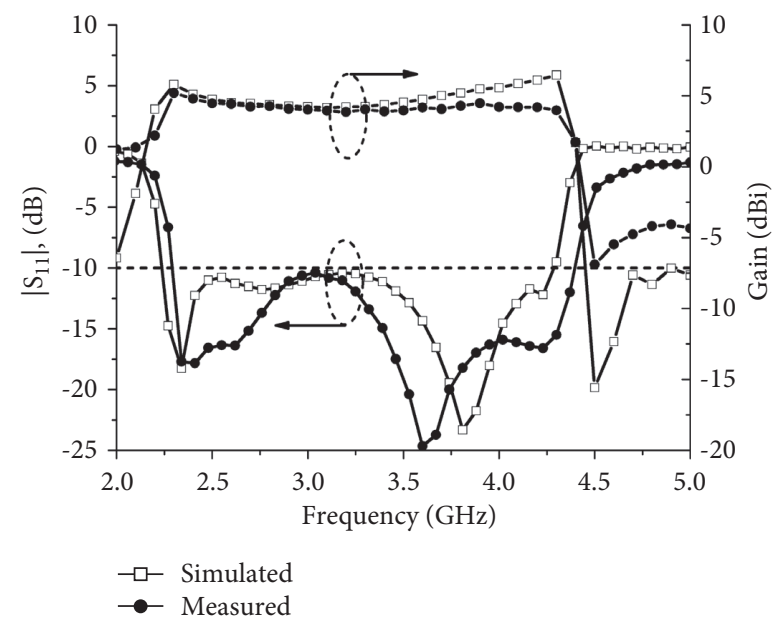

FiguRE 9: Measured and simulated results of reflection coefficients and gains of type A antenna $\left(w_{4}=1.9 \mathrm{~mm}, s_{1}=0.15 \mathrm{~mm}\right.$, and $\left.d_{4}=10.6 \mathrm{~mm}\right)$.

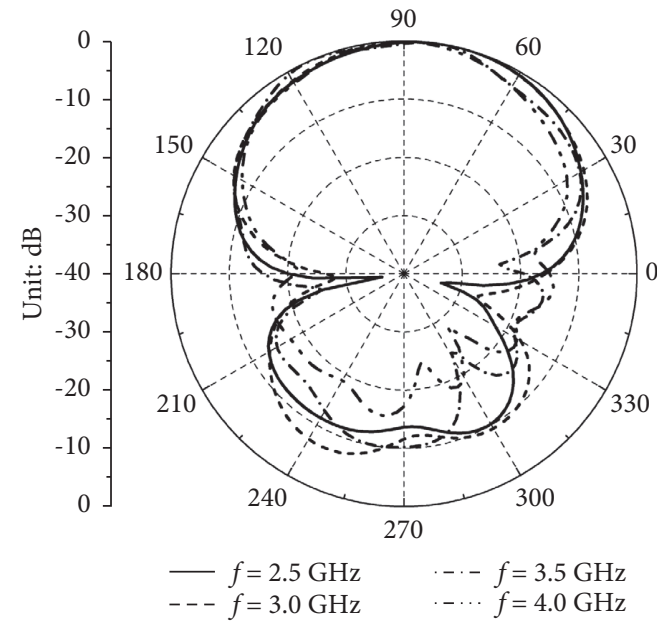

(a)

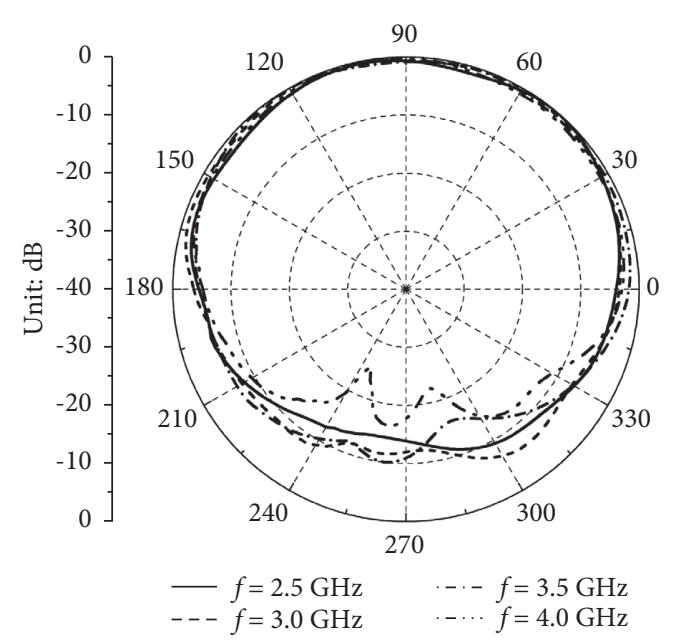

(b)

FIGURE 10: Measured radiation patterns of type A antenna at different frequencies in (a) E-plane (xoy-plane) and (b) H-plane (yoz-plane).

$y$-axis direction. In addition, low back radiation characteristics are achieved by using two closely spaced metallic strips.

The measured $\mathrm{F} / \mathrm{B}$ ratio and radiation efficiency of type $\mathrm{A}$ antenna are shown in Figure 11 for further illustrating the effect of the inner metallic strip. The measured $\mathrm{F} / \mathrm{B}$ ratio is more than $10 \mathrm{~dB}$ in the whole operating frequency band. Compared with the result shown in Figure 6, approximately $1.9 \mathrm{~dB}$ of $\mathrm{F} / \mathrm{B}$ ratio is improved due to the inner metallic strip. The measured radiation efficiency is also shown in Figure 11. For most of the frequency band $(2.3-4.39 \mathrm{GHz})$, the measured radiation efficiency of type A antenna is around $80 \%$.

3.2. Type B Antenna. The photograph of another arrangement mode named type $B$ is shown at the right-hand side of Figure 8 . The simulated and measured reflection coefficients and antenna gains of type B antenna are shown in Figure 12. According to the measured results, a $62 \%$ measured bandwidth ranging from 2.29 to $4.35 \mathrm{GHz}$ is obtained. In the band from 2.29 to $4.35 \mathrm{GHz}$, the minimum gain is at the frequency of $3.1 \mathrm{GHz}$ with a value of $3.4 \mathrm{dBi}$ and the maximum gain at the frequency of $2.3 \mathrm{GHz}$ with a value of $4.9 \mathrm{dBi}$. The measured gain is better than $3.4 \mathrm{dBi}$ in the whole operating frequency band. The antenna gain is slightly changed compared with the results shown in Figure 4.

The simulated and measured radiation patterns of type $B$ antenna in E-plane (xoy-plane) and H-plane (yoz-plane) at 2.5, 3.0, 3.5, and $4 \mathrm{GHz}$ are depicted in Figure 13. Good agreement between the simulations and measurements can also be observed. The main lobes of the radiation patterns are also fixed to the $y$-axis direction in the operating frequency range.

The measured $\mathrm{F} / \mathrm{B}$ ratio and radiation efficiency for type $\mathrm{B}$ antenna are shown in Figure 14. It is observed that the 


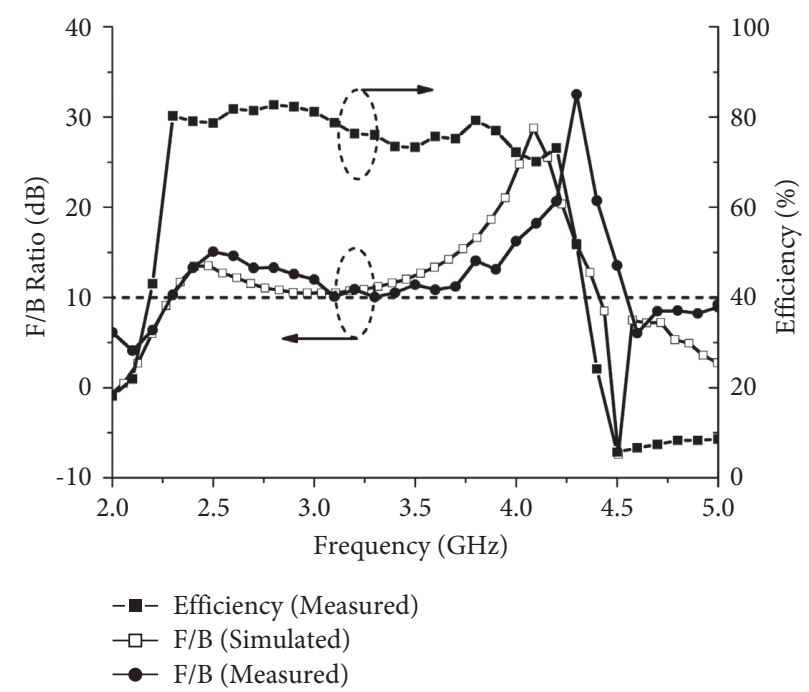

Figure 11: Measured F/B ratio and radiation efficiency of type A antenna.

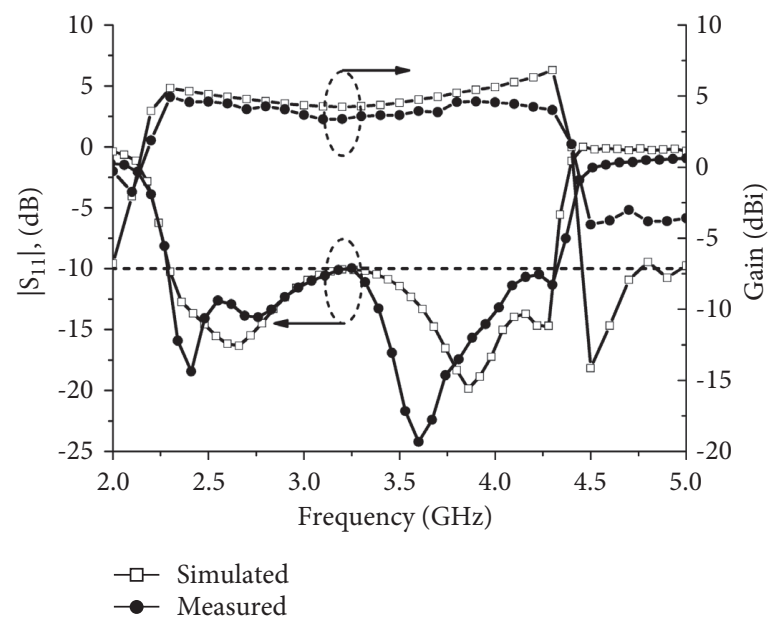

FIGURE 12: Measured and simulated results of reflection coefficients and gains of type B antenna $\left(w_{5}=2.1 \mathrm{~mm}, s_{2}=0.3 \mathrm{~mm}\right.$, and $\left.d_{5}=8 \mathrm{~mm}\right)$.

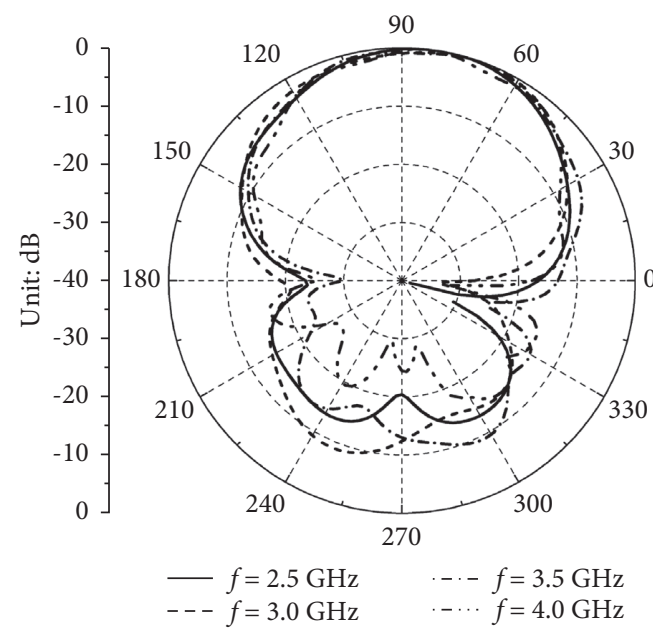

(a)

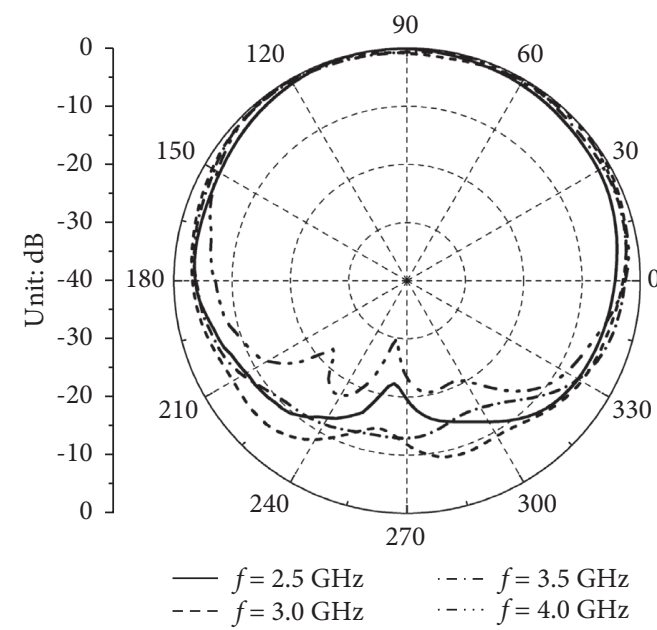

(b)

FIGURE 13: Measured radiation patterns of type B antenna at different frequencies in (a) E-plane (xoy-plane) and (b) H-plane (yoz-plane). 


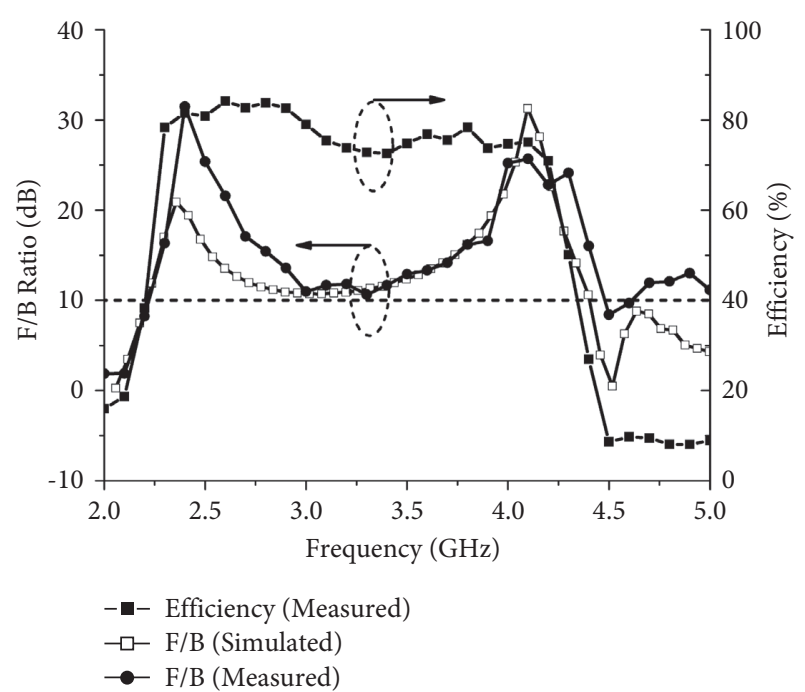

Figure 14: Measured F/B ratios and radiation efficiency of type B antenna.

measured $\mathrm{F} / \mathrm{B}$ ratio is better than $10.6 \mathrm{~dB}$ in the whole operating frequency band. Compared with the results shown in Figure 6, approximately $2.5 \mathrm{~dB}$ of $\mathrm{F} / \mathrm{B}$ ratio is increased due to the outer metallic strip. For most of the frequency band $(2.29-4.35 \mathrm{GHz})$, the measured radiation efficiency of type $\mathrm{B}$ antenna is also around $80 \%$. The radiation efficiency is almost not changed compared with that of the reference antenna in [12].

In order to further illustrate the performances of the improved antennas, Table 1 shows the comparisons among the designed antennas (type A and type B) and the reference antennas in $[11,12]$ in terms of bandwidth, antenna gain, front-to-back ratio, and the antenna sizes. According to the Table 1, the reference antenna shown in [11] has $40.6 \%$ impedance bandwidth. The gain of this antenna is better than $3.3 \mathrm{dBi}$ within the operating frequency range. When a new additional strip is added to the director strip as in [12], although the bandwidth is further improved and a $63.1 \%$ measured bandwidth ranging from 2.29 to $4.4 \mathrm{GHz}$ is achieved, the front-to-back ratio of the antenna is reduced. In order to overcome this problem, two closely spaced metallic strips were adopted as a new reflector to improve the $\mathrm{F} / \mathrm{B}$ ratio of the antenna. Therefore, two arrangement modes of the improved antennas named type A and type $\mathrm{B}$ are designed and measured. The measured results of the two improved designs are also listed in Table 1. According to specifications in Table 1, the impedance bandwidth of type A antenna is about $62.5 \%$ ranging from 2.3 to $4.39 \mathrm{GHz}$, which is approximately equal to the reference antenna in [12]. However, about $0.3 \mathrm{~dB}$ of gain and $2 \mathrm{~dB}$ of $\mathrm{F} / \mathrm{B}$ ratio are improved. Type B antenna can realize a $62 \%$ impedance bandwidth ranging from 2.29 to $4.35 \mathrm{GHz}$. Although the gain of type $B$ antenna is about $3.4 \mathrm{dBi}$ to $4.9 \mathrm{dBi}$, which is approximately equal to the reference antenna in [12], type B antenna achieved a higher $\mathrm{F} / \mathrm{B}$ ratio better than $10.6 \mathrm{~dB}$. Compared with that of the reference antenna in [12], the directivity of type B antenna is greatly improved. Thus, the
TABLe 1: Performance comparison between different antennas.

\begin{tabular}{lcccc}
\hline Antennas & Ref. [11] & Ref. [12] & Type A & Type B \\
\hline Bandwidth $(\mathrm{GHz})$ & $2.29-3.46$ & $2.29-4.4$ & $2.3-4.39$ & $2.29-4.35$ \\
Realized gain $(\mathrm{dBi})$ & $3.3-4.8$ & $3.5-4.9$ & $3.8-5.2$ & $3.4-4.9$ \\
F/B ratio $(\mathrm{dB})$ & $\geq 10$ & $\geq 8.1$ & $\geq 10.1$ & $\geq 10.6$ \\
Sub. sizes $\left(\mathrm{mm}^{2}\right)$ & $60 \times 50$ & $60 \times 50$ & $60 \times 50$ & $60 \times 50$ \\
Ant. Struc. $\left(\mathrm{mm}^{2}\right)$ & $38 \times 24$ & $38 \times 28$ & $38 \times 28$ & $43 \times 30.5$ \\
\hline
\end{tabular}

effectiveness of adopting two closely spaced metallic strips to improve the antenna directivity is verified by using the measured results of the two fabricated antennas. In addition, the F/B ratios of the two fabricated antennas are both improved and better than $10 \mathrm{~dB}$ without changing the overall dimensions and the operating frequency.

\section{Conclusions}

For the printed rectangular loop antenna with two gaps, the impendence matching is improved owing to the new metallic strips added to the main radiation direction. Because of the drawback of narrow characteristics of single strip, the single bent strip at the bottom of antenna cannot provide the wideband reflection capability. Then, the antenna directivity is not good. In this paper, the directivity of the broadband printed unidirectional antenna is improved by using two closely spaced metallic strips as a new reflector to provide wideband reflection capability. In order to demonstrate the effectiveness of the above method, two arrangement modes of the two closely spaced strips as reflector are investigated, fabricated, and measured. According to the measurements results, the bandwidth of type A antenna is about $62.5 \%$ ranging from 2.3 to $4.39 \mathrm{GHz}$ with about $0.3 \mathrm{~dB}$ improvement of the gain and $2 \mathrm{~dB}$ improvement of the $\mathrm{F} / \mathrm{B}$ ratio. The realized gain is about 3.8-5.2 $\mathrm{dBi}$. Type $\mathrm{B}$ antenna can realize a $62 \%$ measured bandwidth ranging from 2.29 to $4.35 \mathrm{GHz}$ and the gain of 3.4-4.9 dBi with a higher $\mathrm{F} / \mathrm{B}$ ratio better than $10.6 \mathrm{~dB}$. Measurement results show that the two closely spaced metallic strips can provide a wideband reflection capability for improving the antenna directivity. The F/B ratios of the two antenna arrangement modes are both better than $10 \mathrm{~dB}$ within the operating frequency band without changing the operating frequency.

\section{Data Availability}

All data included in this study are available upon request to the corresponding author.

\section{Conflicts of Interest}

The authors declare that they have no conflicts of interest.

\section{References}

[1] L. Ge and K. M. Luk, "A wideband magneto-electric dipole antenna," IEEE Transactions on Antennas and Propagation, vol. 60, no. 11, pp. 4987-4991, 2012.

[2] G.-M. Zhang, J.-S. Hong, B.-Z. Wang, G. Song, and P. Zhang, "Compact wideband unidirectional antenna with a reflector 
connected to the ground using a stub," IEEE Antennas and Wireless Propagation Letters, vol. 10, pp. 1186-1189, 2011.

[3] S. Wang, Q. Wu, and D. Su, "A novel reversed T-match antenna with compact size and low profile for ultrawideband applications," IEEE Transactions on Antennas and Propagation, vol. 60, no. 10, pp. 4933-4937, 2012.

[4] T. T. Thai, G. R. DeJean, and M. M. Tentzeris, "Design and development of a novel compact soft-surface structure for the front-to-back ratio improvement and size reduction of a microstrip yagi array antenna," IEEE Antennas and Wireless Propagation Letters, vol. 7, pp. 369-373, 2008.

[5] R. A. Alhalabi and G. M. Rebeiz, "Differentially-fed millimeter-wave yagi-uda antennas with folded dipole feed," IEEE Transactions on Antennas and Propagation, vol. 58, no. 3, pp. 966-969, 2010.

[6] S. Lim and M. F. Iskander, "Design of a dual-band, compact yagi antenna over an EBG ground plane," IEEE Antennas and Wireless Propagation Letters, vol. 8, pp. 88-91, 2009.

[7] S. Lim and H. Ling, "Design of a closely spaced, folded yagi antenna," IEEE Antennas and Wireless Propagation Letters, vol. 5, pp. 302-305, 2006.

[8] S. R. Best, "Improving the performance properties of a dipole element closely spaced to a PEC g plane," IEEE Antennas and Wireless Propagation Letters, vol. 3, pp. 359-363, 2004.

[9] J. J. Yu and S. Lim, "Design of multi-band, compact parasitic array with twisted, helical directors," IEEE Transactions on Antennas and Propagation, vol. 61, no. 1, pp. 444-449, 2013.

[10] R. L. Li, G. DeJean, M. M. Tentzeris, J. Laskar, V. F. Fusco, and R. Cahill, "Unidirectional printed loop antenna," in Proceedings of the 2003 IEEE International Symposium on Antennas, Propagation and EM Theory, pp. 104-107, Beijing, China, November 2003.

[11] J. Wu, Z. Zhao, Z. Nie, and Q. H. Liu, "A broadband unidirectional antenna based on closely spaced loading method," IEEE Transactions on Antennas and Propagation, vol. 61, no. 1, pp. 109-116, 2013.

[12] J. Wu, Z. Zhao, J. Song, X. Zhu, Z. Nie, and Q.-H. Liu, “A wideband printed antenna with unidirectional radiation characteristics," in Proceedings of the 2013 IEEE International Symposium on Antennas and Propagation and USNC-URSI National Radio Science Meeting, pp. 1524-1525, Orlando, FL, USA, July 2013.

[13] S. Zhang, D. A. Genov, Y. Wang, M. Liu, and X. Zhang, "Plasmon-induced transparency in metamaterials," Physical Review Letters, vol. 101, Article ID 047401, 2008. 